\title{
Non-invasive prenatal testing: ethical issues explored
}

\author{
Antina de Jong ${ }^{\star, 1}$, Wybo J Dondorp ${ }^{2}$, Christine EM de Die-Smulders ${ }^{3,4}$, Suzanne GM Frints $s^{3,4}$ \\ and Guido MWR de Wert ${ }^{2}$
}

This paper explores the ethical implications of introducing non-invasive prenatal diagnostic tests (NIPD tests) in prenatal screening for foetal abnormalities. NIPD tests are easy and safe and can be performed early in pregnancy. Precisely because of these features, it is feared that informed consent may become more difficult, that both testing and selective abortion will become 'normalized', and that there will be a trend towards accepting testing for minor abnormalities and non-medical traits as well. In our view, however, the real moral challenge of NIPD testing consists in the possibility of linking up a technique with these features (easy, safe and early) with new genomic technologies that allow prenatal diagnostic testing for a much broader range of abnormalities than is the case in current procedures. An increase in uptake and more selective abortions need not in itself be taken to signal a thoughtless acceptance of these procedures. However, combining this with considerably enlarging the scope of NIPD testing will indeed make informed consent more difficult and challenge the notion of prenatal screening as serving reproductive autonomy. If broad NIPD testing includes later-onset diseases, the 'right not to know' of the future child will become a new issue in the debate about prenatal screening. With regard to the controversial issue of selective abortion, it may make a morally relevant difference that after NIPD testing, abortion can be done early. A lower moral status may be attributed to the foetus at that moment, given the dominant opinion that the moral status of the foetus progressively increases with its development.

European Journal of Human Genetics (2010) 18, 272-277; doi:10.1038/ejhg.2009.203; published online 2 December 2009

Since the discovery of cell-free foetal DNA/RNA (cffDNA/RNA) in maternal plasma in $1997,{ }^{1}$ the possibility to use this cffDNA/RNA for non-invasive prenatal diagnosis (NIPD) has been investigated many times. ${ }^{2-6}$ cffDNA/RNA can be obtained from a maternal blood sample, as early as 4 weeks of gestation, ${ }^{7}$ but currently only reliably so from 7 weeks of gestation. ${ }^{4}$ This development holds the promise of NIPD testing early in pregnancy and without the small, but significant risk of foetal loss that the current invasive procedures of chorionic villus sampling (CVS) and amniocentesis (AP) carry. NIPD testing for the determination of a Y-signal for pregnancies at risk of X-linked disorders and for diagnosis of Rhesus factor status in RhD-negative women is now being translated into clinical practice. ${ }^{4}$ In many European countries, discussion about broader applications of NIPD testing can be expected in the coming years. ${ }^{8,9}$ The feasibility of NIPD for trisomy 21,13 and 18 has already been shown, ${ }^{2}$ but large-scale independent studies are still needed. Sex-chromosomal abnormalities (eg, Turner syndrome (X0) and triple X syndrome $(\mathrm{XXX})$ ) could in principle be diagnosed by NIPD testing as well, ${ }^{4}$ if reliable quantitative tests become available in the future and the maternal 'background' can be excluded from testing. Even if accurate NIPD testing for the mentioned abnormalities becomes possible, the clinical utility of the test remains to be assessed. This includes balancing the benefits to the harms also with regard to its psychological, ethical, legal, social and economic implications. ${ }^{10,11}$ The possible ethical implications of NIPD as a new approach to prenatal testing have so far been reviewed in a few publications. ${ }^{4,8,9,12-17}$ Apart from clear benefits related to avoiding the miscarriage risk of present invasive methods, important potential drawbacks have been mentioned as well. For one thing, proper counselling and informed consent is argued to become more challenging when offering NIPD testing. Moreover, there is a concern that the ease and safety of NIPD may lead to prenatal screening being increasingly conceived as a matter of course, both by those making the offer and by the women undergoing the test. Related to this is the concern that selective abortion of foetuses with minor abnormalities, the wrong sex or unwanted paternity, will become normalized.

This paper aims to expand and refine these ethical evaluations and will add some new ethical perspectives with regard to possible implications of NIPD at present and in the future.

In our view, it is not so much the fact that foetal material used for prenatal testing can be obtained early and non-invasively (allowing easy and safe testing) that would lead to moral challenges. Rather, it is the fact that a technology with these features would be open to being used for testing a potentially much broader range of abnormalities than those included in the presently used method of microscopic chromosome analysis (karyotyping).

Although NIPD testing can also be applied in high genetic-risk families and for the management of pregnancy, the focus of this paper will primarily be on the application of NIPD testing in the screening context. The reason for this focus on prenatal screening is that in the near future, the question if, and if so, in what way NIPD testing is to be applied within prenatal screening strategies should be considered and discussed by policy makers, health care professionals and society at large.

\footnotetext{
1Department of Health, Ethics and Society, Faculty of Health, Medicine and Life Sciences, Research Institute GROW, Maastricht University, Maastricht, The Netherlands; 2Department of Health, Ethics and Society, Faculty of Health, Medicine and Life Sciences, Research Institutes GROW and CAPHRI, Maastricht University, Maastricht, The Netherlands; ${ }^{3}$ Department of Prenatal Diagnosis and Therapy, Research Institute GROW, Maastricht University Medical Center ${ }^{+}$, azM, Maastricht University, Maastricht, The Netherlands; ${ }^{4}$ Department of Clinical Genetics, Research Institute GROW, Maastricht University Medical Center+, azM, Maastricht University, Maastricht, The Netherlands *Correspondence: A de Jong, Department of Health, Ethics and Society, Faculty of Health, Medicine and Life Sciences, Maastricht University, PO BOX 616, Maastricht 6200 MD, The Netherlands. E-mail: at.dejong@hes.unimaas.nl
} 
To avoid confusion, a preliminary remark is needed on terminology. In medicine, 'screening' is often used as referring to a kind of test for risk assessment or disease discovery. However, after the convention in normative and regulatory discourse, we will use 'screening' as referring to any systematic and unsolicited offer of predictive testing (using whatever types of test) involving individuals who themselves have no reason (yet) to seek medical help for the condition in question. ${ }^{18}$ In this broader sense, screening stands in contrast to 'diagnosis' as testing on indication.

\section{CURRENT PRACTICE OF PRENATAL SCREENING}

Prenatal screening is widely accepted and is considered to be important to enable women and their partners to make informed reproductive choices. ${ }^{19}$ In many countries, prenatal screening strategies consist of two elements. ${ }^{20,21}$

First, screening for Down's syndrome (trisomy 21) and other aneuploidies by means of a risk-assessment test and, in case of a positive initial result, a diagnostic invasive prenatal test is offered for further diagnosis such as CVS at 11-13 weeks of gestation or amniocentesis at 15-18 weeks of gestation. These invasive procedures may induce a miscarriage in $0.3-1.0 \%$ of the pregnancies investigated. ${ }^{20,22,23}$ The risk-assessment test generally combines biochemical markers in maternal serum and ultrasound markers (nuchal translucency measurement) to determine whether there is a higher risk of having a child with DS or other aneuploidies. If so, a diagnostic test, such as conventional karyotyping (cytogenetic analysis) or rapid aneuploidy detection (DNA analysis), is offered to confirm or exclude the presence of a chromosomal abnormality in the foetus. ${ }^{20,22-24}$

Second, an ultrasound investigation is offered at week 18-20 of gestation to identify major structural, congenital malformations and also to look for so-called 'soft' markers that increase the risk for chromosomal or genetic syndromes. When there is an increased risk, a more detailed ultrasound scan and/or invasive prenatal or postnatal diagnostic tests are needed for further diagnosis. ${ }^{20}$

\section{POSSIBLE DYNAMICS OF NIPD TESTING}

\section{NIPD testing in the context of prenatal screening}

Research into NIPD testing has mainly focused on those chromosomal abnormalities currently diagnosed with karyotyping as part of the prenatal screening strategies. Wright distinguishes five possible applications of NIPD testing in this context: as an additional test to improve overall risk assessment, as an intermediate test between risk assessment and invasive diagnostic testing for high-risk pregnancies, as a replacement for current risk-assessment tests, as a replacement for current invasive diagnostic tests or as a replacement for both riskassessment and diagnostic tests. ${ }^{8}$ As structural abnormalities per se are not identified through NIPD testing, its possible introduction would not affect current ultrasound screening.

In the ethical discussions thus far, NIPD testing as a substitution for the present combination of risk assessment and invasive diagnostic testing seems generally to be regarded as ultimately the most likely scenario. ${ }^{4,8,12,14,16}$ Indeed, if NIPD tests can easily, safely, reliably and cheaply diagnose chromosomal abnormalities such as trisomy 21 in early pregnancy, this will entail abolishment of the current two-steptesting process.

\section{Increasing number of prenatal diagnostic tests}

An important implication of NIPD testing as a one-step approach to prenatal screening is that prenatal diagnostic tests will be offered to all pregnant women, instead of to a limited high-risk group. This increase in the number of diagnostic tests does not mean an increase in the extent of the actual group that is approached with an unsolicited prenatal test offer: only the nature of this offer will change. Direct access to diagnostic testing has the advantage of avoiding false positive and false negative outcomes of risk assessment. This means that all pregnant women can profit from the more certain diagnostic test results for reproductive decision making, which enhances their reproductive autonomy. ${ }^{25}$ However, a morally relevant aspect is also that a diagnosis early in pregnancy may have the drawback of increasing the burden of knowledge and choice for the women concerned. As chances of an affected pregnancy ending in miscarriage decrease with gestational age, early testing will more often burden women with 'unnecessary' decision making concerning pregnancies that may spontaneously miscarry. ${ }^{8,26}$

\section{INFORMED CONSENT FOR NIPD TESTING: THE NATURE OF THE TEST}

Concern has been expressed that offering NIPD testing on a wide scale would undermine informed consent. ${ }^{8,12-15}$ If current two-step testing is substituted by a single diagnostic test, it is supposed to be more difficult to provide all pregnant women with adequate information and pre-test counselling, 'despite being conceptually easier. ${ }^{8}$ The quote refers to the fact that one-step screening can do without the concept of risk, which most people find difficult to handle. But why would informed consent in such an approach still be more difficult? The idea behind this concern may be that in two-step screening information about the challenges and possible outcomes of further testing need only be given to the small subset of women with a positive screen result, whereas all necessary information must be given at once in one-step screening. However, this view is morally problematic, as it ignores that risk assessment is potentially a first step in a sequence of testing with exactly the same possible implications as one-step screening. As the information to be given before risk assessment should not be limited to this first 'innocent' step, it is unclear why one-step screening as such would make information and pre-test counselling more difficult. However, a further assumption behind the concern about informed consent may be that introducing NIPD testing will be combined with enlarging the scope of prenatal screening. As we will argue later on in this article that would indeed make informed consent more challenging. But the point we want to make here is that there is nothing in the nature of the NIPD test itself (its one-step character) that would lead to this greater challenge. Of course, this is not to deny that in current practice information, counselling and consent are often inadequately dealt with ${ }^{27-30}$ and this may also be the case with regard to NIPD testing. However, as long as NIPD testing will be offered for the same range of abnormalities as in the present two-step approach to prenatal screening, there is no reason to assume that these problems will be larger than they already are.

\section{NORMALIZATION OF NIPD TESTING}

A further concern that has been raised is that the introduction of NIPD as a risk-free procedure may lead to 'normalization' of prenatal testing. In addition to what has more generally been referred to as a 'technological imperative', the mechanism behind this would be driven by the specific features of NIPD testing., ${ }^{4,8,12-14,31}$ A distinction can be made between normalization of the offer and of the uptake, although these aspects are of course related.

Normalization of the offer means that NIPD tests will be portrayed by clinicians and experienced by pregnant women as part of routine antenatal care, because, due to its ease and safety, it seems to be a rather trivial test to offer and take. This may lead to normalization of uptake, ranging from a rather thoughtless uptake to women feeling 
socially pressurized to be tested. ${ }^{8,13,32}$ If this implies testing without informed consent, uptake cannot be said to be the result of nor to be promoting autonomous reproductive decision making. Of course, an increase in uptake does not necessarily indicate its normalization, as it might also reflect a conscious positive reception of the new possibilities of NIPD testing by pregnant women, ${ }^{33}$ and thus signify the achievement of the aim to 'facilitate parental reproductive choice.' ${ }^{8}$

However, as it has often been observed that in current prenatal screening programmes, test uptake is not always on the basis of adequate understanding, ${ }^{32}$ there is indeed reason for concern that the ease and safety of NIPD testing will make this even more difficult to achieve. This concern is reinforced by the finding that health care professionals seem inclined to the view that a less stringent standard of informed consent would suffice for NIPD testing. ${ }^{34}$ We find this problematic because, iatrogenic risks aside, the possible outcomes and consequences of invasive and non-invasive diagnostic testing remain the same. We, therefore, agree that introducing NIPD testing should not be regarded as a reason for loosening present guidelines for informed consent. ${ }^{34}$

\section{NORMALIZATION AND TRIVIALIZATION OF EARLY SELECTIVE ABORTION}

Easy, safe and early NIPD testing might lead to an increase in the number of affected foetuses aborted. ${ }^{13}$ In addition to this possible quantitative implication, concern has been expressed about a qualitative change in selective abortion procedures as well. As Hall et al $l^{13}$ comment: 'More generalized use of non-invasive testing could facilitate selective terminations of pregnancy in a range of conditions hitherto not diagnosed prenatally and where the arguments for and against termination may not have received sufficiently scrutiny'. We will consider this possible 'trivialization of abortion' in relationship to the possible earlier timing of selective abortion because of NIPD testing.

NIPD testing early in pregnancy may on balance offer important benefits for the women involved. It enables earlier reassurance and, therefore, allows for 'better opportunities for prenatal bonding' ${ }^{14}$ for those women who might experience their pregnancy being 'tentative' during the testing period. At the same time, early testing enables a longer period for the decision-making process after a positive test result, which may be valued positively by some women as well. In addition, if a positive test result leads to a choice for selective abortion, this termination might be physically and psychologically less burdening when carried out earlier in pregnancy. ${ }^{13}$ These implications for women may support the view and the experience that early testing and abortion, even if performed for abnormalities hitherto not prenatally diagnosed, may be less problematic. Empirical research is needed to illuminate women's attitudes and preferences in this regard.

The early timing of abortion is also ethically relevant because of different opinions about the moral status of the embryo or early foetus. ${ }^{35,36}$ The timing of abortion is only ethically insignificant if an absolute or high moral status is assigned to the embryo right from the start, or, conversely, when there is no independent status attributed to the embryo/foetus at all. However, the dominant opinion in most western countries, often also reflected in legislation, is that the moral status of the embryo/foetus progressively increases with its development (the gradualist view). ${ }^{26} \mathrm{~A}$ variant of this view refers to transitional moments at specific stages in embryonic or foetal development. As cffDNA/RNA can currently reliably be obtained from a maternal blood sample from 7 weeks of gestation ( 5 weeks of development), the beginning of cerebral development at 6 weeks (40 days) ( 8 weeks of gestation) is of special importance in this connection. In some religions, this developmental stage is associated with ensoulment. ${ }^{37,38}$ Adherents of this '40 days position' would presumably have no or less moral objections to selective abortion before that specific point in time, because of the lower or absent moral status of the foetus before that moment. More generally, adherents of a gradualist view will favour the possibility of earlier selective abortions after NIPD testing. It is conceivable that this time factor might as well be relevant for the scope of the conditions for which NIPD testing will be applied.

To summarize, the lower moral status of the embryo and the possibly less traumatic psychological and emotional implications of early abortion might influence and to some extent justify a certain broadening of the scope of NIPD testing.

\section{CHANGING THE SCOPE OF PRENATAL TESTING}

\section{Narrow or broad?}

NIPD testing is feared to be applied for more and also for increasingly minor abnormalities, without adequate justification: the so-called 'specification creep. ${ }^{8,13}$ The reasoning behind this concern seems to be that the invasiveness of current diagnostic testing prevents expansion of its scope. Supposedly, one would not take the risk of losing a healthy child with invasive testing, but for the detection of (a high risk for) a really serious disease. In this view, the ease, safety and early moment of NIPD testing could be an incentive to apply NIPD testing for more and less serious conditions in the future. One could, however, also reason the other way around: the effort and the risk of the invasive procedure may be an incentive to test for as much abnormalities as possible, just to make this risk more proportional and to provide a more firm justification. ${ }^{39,40}$

Karyotyping has been the 'Gold Standard' for diagnostic testing in the screening context for almost half a century now and also seems to be the reference point for the scope of NIPD testing. ${ }^{8}$ When NIPD testing implies abolishment of the current risk assessment, a limitation of the scope of NIPD testing to the chromosomal abnormalities diagnosed by karyotyping seems no longer evident. Furthermore, the issue whether the scope of invasive diagnostic testing should be narrower or broader than the current scope has already been under discussion for some years now. ${ }^{41-43}$ Limitation to some well-defined anomalies, such as trisomy 21,13 and 18 , has been proposed, as well as an expansion of the scope by, for example, array-based comparative genomic hybridization. ${ }^{44,45}$ One of the main reasons to offer narrow testing is to reduce the probability of unexpected and clinically unclear findings. These can lead to difficult pre- and post-test counselling situations, impair informed decision making and make decisions regarding selective abortion emotionally more difficult and morally controversial. A broader scope is mainly supported by the argument that prenatal testing should focus on detecting any possible (severe) disability, irrespective of its cause and depending on the woman's or couple's choice. If people prefer to have maximum information, withholding information would deprive them of their autonomous reproductive choice. ${ }^{42}$

The above shows that the features of NIPD testing in itself do not necessitate a specific scope of testing: it could be narrow as well as broad.

\section{NIPD testing for heterogeneous abnormalities}

Although not feasible in the near future, a possible future expansion of the scope of NIPD testing has been brought up several times. ${ }^{4,8,12}$ If it might indeed become possible to include a kind of total genome sequencing in NIPD testing, the scope of NIPD testing in the context of common prenatal screening could exceed that of karyotyping. Then its scope might not only include (mono)genetic and/or congenital 
disorders, but also complex and late-onset disorders. ${ }^{4,8,12}$ Such an increase in scope is assumed to be 'more ethically problematic'. ${ }^{8}$ It has proven to be next to impossible to reach consensus about the definition of a list of diseases that are serious enough to test prenatally and to justify selective abortion - even if performed early. Partly because of variable expression, changes over time because of evolving treatment and personal situation, the severity of diseases is perceived differently. Still, broad ethically relevant categories of diseases and genotypes may be discerned: causative genetic traits for congenital disorders with clear clinical consequences, causative genetic traits for late-onset diseases, genetic variants associated with increased susceptibility to disease and carriership of recessive disorders. Inclusion of all these categories in an NIPD-testing array will lead to different ethical challenges, which will be discussed below.

\section{INFORMED CONSENT FOR NIPD TESTING: THE SCOPE OF THE TEST}

\section{Generic consent}

If an NIPD test will be aimed at detection of different categories of disorders simultaneously, this would complicate informed consent, counselling and decision making. Testing for (many) heterogeneous abnormalities at once would require more, more elaborate and detailed information. In addition, findings of unclear significance, which are always present in complex testing, would require special attention. Altogether, this could lead to an 'information overload', which could impair the decision-making process. ${ }^{46}$ More intensive counselling would be needed, which might be too time consuming and expensive if offered on a wide scale. Therefore, the requirement of extensive informed consent for broad NIPD testing may be really problematic to comply with.

As regards this subject, the alternative of generic consent has been proposed. ${ }^{47}$ This concept 'would emphasize broader concepts and common-denominator issues in genetic screening' by providing 'general information to obtain consent for the screening and much more detailed information on specific conditions only after they have been detected. ${ }^{47}$

A conceivable way of obtaining generic consent for an NIPD test with a broader scope would be to inform women in more general terms about categories of abnormalities included. On the basis of this information, women might be given the opportunity to indicate what kinds of abnormalities they would prefer to be told about. ${ }^{26}$ This approach has already been discussed with regard to current karyotyping. ${ }^{22}$ Some kind of generic consent seems to be inevitable when offering a broad NIPD test. The question is whether this is a justifiable way of executing the principle of respecting reproductive autonomy, because it endangers the feasibility of truly informed choices. ${ }^{26}$

In this respect, offering broad NIPD testing to all pregnant women may be seen as the molecular equivalent of the second trimester ultrasound scan. As the prenatal ultrasound scan may also detect a broad range of foetal defects, informed consent would at least require informing women before the scan about the variety of test results they could possibly encounter and have to deal with. Although a lack of proper informed consent has been reported in this context as well, ${ }^{48,49}$ this has been a remarkably less debated subject than with regard to risk-assessment and invasive prenatal diagnostic tests. ${ }^{27-30,50}$ The implementation of informed consent for these latter two prenatal tests has been proven to be inadequate several times, showing a discrepancy between theory and practice in this regard. Hence, there is a need to discuss the model and the implementation of informed consent for any present and future prenatal screening offer. The question will ultimately be to what extent the condition of informed consent is really valued: if the features, scope and implementation of prenatal testing are adjusted to the requirements of proper informed consent, the value of this condition will be reinforced. If it is the other way around, a declared adherence to the value of informed consent may well be deluding. ${ }^{51}$

\section{Decision-making process and the right not to know}

NIPD testing for a broad and heterogeneous range of abnormalities would generate a large amount of information and inevitably include findings the significance of which would be difficult, if at all, to interpret and explain. Unclear findings might lead to extensive diagnostic follow-up and even to the testing of parents to establish inheritance of unusual results, which may confront parents with unexpected findings about themselves as well. This leads to the question whether such knowledge would be harmful or beneficial for the parents and the future child. Unclear findings regarding the foetus could lead to confusion and unnecessary anxiety for parents, which is likely to persist throughout the pregnancy and into the postnatal period if the pregnancy is continued. A decision to terminate a wanted pregnancy on a basis of unclear testing results may be associated with 'particular feelings of guilt. ${ }^{42}$ On the one hand, patient autonomy may still be an important consideration for providing women with more information about their foetus, if they prefer so. ${ }^{52}$ On the other hand, it has been asserted that prenatal screening for 1000 genetic variations with $99.9 \%$ accuracy for true positives at once may lead to the consequence that 'every foetus will be identified as abnormal', thereby undermining the aim of this screening. ${ }^{43}$ These different views again underline the necessity of empirical research into women's attitudes, preferences and expected burdens regarding (broad) NIPD testing to assess the requirement of proportionality.

The issue of the right not to know of the future child might become a relevant issue in case of testing for monogenetic late-onset diseases and for increased susceptibility to diseases. Unsolicited knowledge of these traits would be an invasion of the autonomy of future children who have prenatally been diagnosed. If NIPD testing included these different kinds of disorders and the pregnancy was continued, it would resemble the possible future scenario of whole genome profiling of newborns, which would not be directed at any particular disease, but would reveal information about many and heterogeneous abnormalities, including late-onset diseases. ${ }^{53}$ As such, the resemblance of broad NIPD testing with newborn profiling indicates a blurring of the distinction between reproductive and non-reproductive screening. Testing foetuses would de facto amount to testing (future) children. Disclosure of findings about late-onset diseases in the neonatal screening context is considered to be incompatible with the widely, but not universally, endorsed maxim that predictive genetic testing should in principle be avoided in minors to protect their autonomy and privacy. ${ }^{53,54}$ The only accepted exception is if medical interventions are available to alter the course of the disease. ${ }^{53,54}$

\section{NIPD TESTING FOR NON-MEDICAL REASONS}

NIPD testing for establishing sex or paternity, which is currently commercially offered, and subsequent selective abortion if the foetus is of the 'wrong' sex or from the 'wrong' biological father are generally thought to be problematic. ${ }^{8,14,55-57}$

With regard to gender testing, one concern is the preference in some societies of having a boy over a girl, which could have disrupting effects on those societies if selective abortion of female foetuses would be performed on a large scale. In that case, society could have good reason to restrict individual choice, because it undermines a public good. ${ }^{58}$ Indeed, in some countries, sex selection is prohibited for 
exactly this reason. ${ }^{59}$ If sex selection would reflect a discrimination against women and systematically reinforce that bias, this could constitute a moral and legal injustice to be prevented. ${ }^{60}$ However, sex selection itself does not necessarily entail a discriminatory act. It could as well be an act of responsibility for a future girl's interest (eg, to guard it from being treated unjustly) even if this motive would arise against the background of a discriminatory society. ${ }^{36,61}$ Furthermore, couples can have personal motives for sex selection, such as family balancing. Some reject this as showing that children are increasingly seen as 'commodities'. However, sex selection for family balancing can also be valued as an opportunity for reproductive autonomy. ${ }^{62}$

With regard to prenatal paternity testing, there are hardly any medical applications, except in case of inherited diseases in which the underlying gene defect is not known and prenatal diagnostic tests cannot, therefore, be used. ${ }^{16}$ Non-medical reasons include ambiguous paternity in case of women with more than one sexual partner who are unsure of the actual father, and women who may be pregnant as the result of rape. In the latter case, paternity testing is not disputed, whereas in the former case paternity testing has been criticized. ${ }^{8,13,14}$

It has been suggested to counsel the women involved about the relative significance of biological kinship. ${ }^{14}$ To the extent that this is carried out with the aim of reducing the number of prenatal paternity tests, this approach strikes us as morally problematic. Counselling should be respectful of how the woman herself perceives the emergency situation leading to her request; counsellors should not try to defuse the problem by defining it away. We also suspect that reluctance to provide prenatal paternity testing may be prompted by an implicit condemnation of a promiscuous life. This would clearly be moralistic and unprofessional.

One should also realize that without paternity testing, women could feel compelled to terminate the pregnancy anyhow. Or women could feel compelled to continue the pregnancy, with the consequence of having a child fathered by the wrong man. Prenatal paternity testing may, therefore, lead to the least harm for the woman involved and be morally justified. ${ }^{63}$

Although personal motives for sex selection and paternity testing may be ethically controversial, abortion is allowed under various legal rules regarding social termination. ${ }^{16,61}$ In the case of NIPD testing, views regarding the moral status of the early embryo will be of relevance with regard to both reasons for selective abortion.

\section{CONCLUSION}

On the one hand, women taking part in prenatal screening can profit from the ease, safety and early moment of NIPD testing. The introduction of a test with these features has ethically favourable consequences: absence of iatrogenic miscarriage because of the test, earlier reassurance, a longer period for decision-making and the possibility of an early abortion, which may be physically and psychologically less burdening and ethically less problematic because of presumed lower moral foetal status. On the other hand, should NIPD testing for a broader scope of abnormalities become possible in the future, this will complicate the ethical issues regarding NIPD testing. Informed consent will become far more challenging - if attainable at all. Moreover, should NIPD testing become available for a wide range of disorders including late-onset diseases, this may lead to the same ethical difficulties as with regard to wide range testing of newborns, in which the dominant view is that the child's right not to know should be respected. It is difficult to see how this respect can be upheld when, after broadening prenatal testing, children will be born with a positive test result for a serious late-onset disease. The debate about the ethical challenges of broad genetic testing is currently conducted in the contexts of neonatal screening and invasive prenatal testing. In this article, we have shown that the same issues will present themselves even more forcefully should broad NIPD testing become possible. A proactive further analysis of these issues is urgently needed. As we have stressed, this also requires empirical research into pregnant women's attitudes, needs and preferences concerning different modalities of prenatal testing.

\section{CONFLICT OF INTEREST}

The authors declare no conflict of interest.

\section{ACKNOWLEDGEMENTS}

This article is the result of two research projects: Research project number 70.1.061b of the Centre for Society and Genomics in the Netherlands, funded by the Netherlands Genomics Initiative; Research project number 120510006 of the NWO Zonmw Prevention Fund.

1 Lo YMD, Corbetta N, Chamberlain PF et al: DNA in maternal plasma and serum. Lancet 1997; 350: 485-487.

2 Fan HC, Blumenfeld YJ, Chitkara U, Hudgins L, Quake SR: Noninvasive diagnosis of fetal aneuploidy by shotgun sequencing DNA from maternal blood. PNAS 2008; 105 : 16266-16271.

3 Lo YMD, Chiu RWK: Prenatal diagnosis: progress through plasma nucleic acids. Nat Rev Genet 2007; 8: 71-77

4 Wright $\mathrm{CF}$, Burton $\mathrm{H}$ : The use of cell-free fetal nucleic acids in maternal blood for noninvasive prenatal diagnosis. Hum Reprod Update 2009; 15: 139-151.

5 Geifman-Holtzman 0, Berman JO: Prenatal diagnosis: update on invasive versus noninvasive fetal diagnostic testing from maternal blood. Expert Rev Mol Diagn 2008; 8: 727-751.

6 Maron JL, Bianchi DW: Prenatal diagnosis using cell-free nucleic acids in maternal body fluids: a decade of progress. Am J Med Genet 2007; 145C: 5-17.

7 Illanes S, Denbow M, Kailasam C, Finning K, Soothill P: Early detection of cell-free fetal DNA in maternal plasma. Early Hum Dev 2007; 83: 563-566.

8 Wright C: Cell-free fetal nucleic acids for non-invasive prenatal diagnosis. Report of the UK expert working group, PHG Foundation, 2009, http://www.phgfoundation.org/ download/ffdna/ffDNA_report.pdf. Accessed March 42009.

9 Wright CF, Chitty LS: Cell-free fetal DNA and RNA in maternal blood: implications for safer antenatal testing. BMJ 2009; 339: b2451.

10 Grosse SD, Khoury MJ: What is the clinical utility of genetic testing? Genet Med 2006; 8: 448-450.

11 Sanderson S, Zimmern R, Kroese M, Higgins J, Patch C, Emery J: How can the evaluation of genetic tests be enhanced? Lessons learned from the ACCE framework and evaluating genetic tests in the United Kingdom. Genet Med 2005; 7: 495-500.

12 Benn PA, Chapman AR: Practical and ethical considerations of noninvasive prenatal diagnosis. JAMA 2009; 301: 2154-2156.

13 Hall A, Bostanci A, John S: Ethical, legal and social issues arising form cell-free fetal DNA technologies. Appendix III to the report: Cell-free fetal nucleic acids for noninvasive prenatal diagnosis, PHG Foundation 2009, http://www.phgfoundation.org/ download/ffdna/ffDNA appendix.pdf. Accessed March 42009.

14 Newson AJ: Ethical aspects arising from non-invasive fetal diagnosis. Sem Fetal Neonat Med 2008; 13: 103-108.

15 Schmitz D, Netzer C, Henn W: An offer you can't refuse? Ethical implications of noninvasive prenatal diagnosis. Nat Rev Genet 2009; 10: 515.

16 Smith RP, Lombaard H, Soothill PW: The obstetrician's view: ethical and societal implications of non-invasive prenatal diagnosis. Prenat Diagn 2006; 26: 631-634.

17 Schmitz D, Henn W, Netzer C: Commentary: no risk, no objections? Ethical pitfalls of cell-free fetal DNA and RNA testing. BMJ 2009; 339: b2690.

18 Health Council of the Netherlands: Genetic Screening. The Hague: Health Council, 1994. Publication no. 1994/22.

19 Health Council of the Netherlands: Prenatal Screening (2); Down's Syndrome, Neural Tube Defects. The Hague: Health Council of the Netherlands, 2004. Publication no. 2004/06.

20 Bui T-H, Meiner V: State of the art in prenatal diagnosis; in: Leuzinger-Bohleber M, Engels E-M, Tsiantis J (eds): The Janus Face of Prenatal Diagnostics. A European Study Bridging Ethics, Psycholanalysis, and Medicine. London: Karnac Books, 2008, pp 61-86.

21 Saller DN, Canick JA: Current methods of prenatal screening for Down Syndrome and other fetal abnormalities. Clin Obstet Gynecol 2008; 51: 24-36.

22 Health Council of the Netherlands: Prenatal Screening: Down's Syndrome, Neural Tube Defects, Routine-Ultrasonography. The Hague: Health Council of the Netherlands, 2001. Publication no 2001/11E. 
23 Mujezinovic F, Alfirevic Z: Procedure-related complications of amniocentesis and chorionic villous sampling: a systematic review. Obstet Gynecol 2007; 110: 687-694.

24 ACOG: ACOG Practice Bulletin No. 88 (2007) invasive prenatal testing for aneuploidy. Obestet Gynecol 2007; 110: 1459-1467.

25 Lo DYM, Chiu RWK: Noninvasive prenatal diagnosis of fetal chromosomal aneuploidies by maternal plasma nucleic acid analysis. Clin Chem 2008; 54: 461-466.

26 de Wert G: Looking ahead. Reproductive technologies, genetics and ethics. Amsterdam: Thela Thesis, 1999 (in Dutch).

27 van den Berg M: Decision Making on Prenatal Screening. Wageningen: Ponsen \& Looijen B.V., 2006.

28 Marteau TM, Dormandy E: Facilitating informed choice in prenatal testing: how well are we doing? Am J Med Genet 2001; 106: 185-190.

29 Seavilleklein V: Challenging the rhetoric of choice in prenatal screening. Bioethics 2009; 23: 68-77.

30 van Zwieten M: The Target of Testing. Dealing with 'Unexpected' Findings in Prenatal Diagnosis. Amsterdam: Uitgeverij Buijten \& Schipperheijn, 2006.

31 van den Heuvel A, Chitty L, Dormandy E, Newson A, Deans Z, Marteau TM: Informed choice in prenatal testing: a survey among obstetricians and gynaecologists in Europe and Asia. Prenat Diagn 2008; 28: 1238-1244.

32 Green J, Hewison J, Bekker H, Bryant L, Cuckle H: Psychosocial aspects of genetic screening of pregnant women and newborns: a systematic review. Health Technol Assess 2004; 8: iii, ix-x, 1-109. Review.

33 Kooij L, Tymstra T, van den Berg P: The attitude of women toward current and future possibilities of diagnostic testing in maternal blood using fetal DNA. Prenat Diagn 2009; 29: 164-168.

34 van den Heuvel A, Chitty L, Dormandy $\mathrm{E}$ et al: Will the introduction of non-invasive prenatal diagnostic testing erode informed choices? An experimental study of health care professionals. Patient Educ Couns 2009, doi:10.1016/j.pec.2009.05.014.

35 Gillon R: Is there a 'new ethics of abortion'? J Med Ethics 2001; 27: ii5-ii9.

36 Pennings G, de Wert G: Evolving ethics in medically assisted reproduction. Hum Reprod Update 2003; 9: 397-404.

37 Aramesh K: Abortion: an Islamic ethical view. Iran J Allergy Asthma Immunol 2007; 6 (Suppl. 5): 29-33.

38 Mackler AL: Introduction to Jewish and Catholic Bioethics: A Comparative Analysis. Georgetown: Georgtown University Press, 2003.

39 ten Kate LP: Snelle prenatale diagnostiek van chromosomale fwijkingen;beperkingen en mogelijkheden. NTVG 2006; 150: 1608-1612 (in Dutch).

40 van den Veyver I, Beaudet AL: Comparative genomic hybridization and prenatal diagnosis. Curr Opin Obstet Gynecol 2006; 18: 185-191.

41 Bui T-H: Prenatal cytogenetic diagnosis: gone FISHing, BAC soon! Ultrasound Obstet Gynecol 2007; 30: 247-251.

42 Ogilvie CM, Yaron Y, Beaudet AL: Current controversies in prenatal diagnosis 3: for prenatal diagnosis, should we offer less or more than metaphase karyotyping? Prenat Diagn 2008; 29: 11-14.

43 Shuster E: Microarray genetic screening: a prenatal roadblock for life? Lancet 2007; 369: 526-529.
44 Sahoo T, Cheung SW, Ward P et al: Prenatal diagnosis of chromosomal abnormalities using array-based comparative genomic hybridization. Genet Med 2006; 8: 719-727.

45 Shaffer LG, Coppinger J, Alliman S et al: Comparison of microarray-based detection rates for cytogenetic abnormalities in prenatal and neonatal specimens. Prenat Diagn 2008; 28: 789-795.

46 de Wert G, Dondorp W: Ethical issues; in: van Vugt M, Shulman K (eds): Prenatal Medicine. New York/London: Taylor \& Francis, 2006, pp 575-604.

47 Elias S, Annas GJ: Generic consent for genetic screening. N Engl J Med 1994; 330 : 1611-1613.

48 de Kort S: Verkeerde routine. 20-wekenecho is zoektocht naar alle mogelijk afwijkingen geworden. Medisch Contact 2008; 63: 563. (in Dutch).

49 Laror J, Begley C: Fetal anomaly screening: what do women want to know? J Adv Nurs 2006; 55: 11-19.

50 Favre R, Moutel G, Duchange $\mathrm{N}$ et al: What about informed consent in first-trimester ultrasound screening for down syndrome? Fetal Diagn Ther 2008; 23: 173-184.

51 Clarke AJ: Prenatal genetic screening: paradigms and perspectives; in: Harper PS Clarke AJ (eds):: Genetics, Society and Clinical Practice. Oxford: BIOS Scientific Publishers, 1997, pp 119-140.

52 Friedman JM: High-resolution array genomic hybridization in prenatal diagnosis. Prenat Diagn 2009; 29: 20-28.

53 Human Genetics Commission and the UK National Screening Committee (Joint Working Group): Profiling the newborn: a prospective gene technology? London: Human Genetics Commission, 2005.

54 Hayeems RZ, Bytautas JP, Miller FA: A systematic review of the effects of disclosing carrier results generated through newborn screening. J Genet Counsel 2008; 17: 538-549.

55 Bianchi DW: At-home fetal DNA gender testing: caveat emptor. Obstet Gynecol 2006; 107: 216-218

56 Hall S, Reid E, Marteau TM: Attitudes towards sex selection for non-medical reasons: a review. Prenat Diagn 2006; 26: 619-626.

57 Rogers W, Ballantyne A, Draper H: Is sex-selective abortions morally justified and should it be prohibited? Bioethics 2007; 21: 520-524.

58 Buchanan A, Brock D, Daniels N, Wikler D: From Chance to Choice. Genetics and Justice. Cambridge: Cambridge University Press, 2000.

59 Zhu WX, Lu L, Hesketh T: China's excess males, sex selective abortion, and one child policy: analysis of data from 2005 national intercensus survey. BMJ 2009; 338: b1211.

60 Toebes B: Sex selection under international human rights law. Med Law Internat 2008; 9: 197-225.

61 Health Council of the Netherlands: Sex-selection for non-medical reasons. The Hague: Health Council of the Netherlands, 1995. Publication no. 1995/11E.

62 Moazam F: Feminist discourse on sex screening and selective abortion of female foetuses. Bioethics 2004; 18: 269-9702.

63 Bayertz K: Pränatale Vaterschaftsdiagnostik und selective Abtreibung. Ethische Überlegungen zu einem schwierigen Fall aus der genetischen Beratungspraxis. 9 Jahrbuch für Recht und Ethik 2001; 9: 119-129 (in German). 